\title{
Urinary Mucopolypeptides and Mucoproteins in Cancer
}

\author{
II. An Acid Mucopolypeptide Characteristic of Cancer*
}

By

\author{
Hajime Masamune, Sen-itiroh Hakomori and Takasi Sugo \\ (正 宗 一) (箱守 仙一郎) (須 哏 呆)
}

From the Medico-chemical Institute, Tohoku University, Sendai

(Received for publication, February 20, 1959)

In the preceding article ${ }^{1)}$ we attempted to discriminate the urinary mucoproteins of cancer patients from those of normals and of patients suffering from inflammatory diseases by comparing polarographic waves of them or their various derivatives or by rough fractionation of polarographically active factors of whole urine by the aid of an anion exchanger column. However, our intention to discover any specific change of mucoproteins in cancer was not accomplished, so that efforts were made ever since for much more detailed fractionation of the urinary muco-substances followed by precise chemical analysis of the fractions.

Retrospectively, one of the outstanding features of change in serum or in urine in the case of cancer or inflammation has been the marked elevation of the mucoprotein level, since Lustigia) and later on Nilsson ${ }^{21}$ and West $^{3 /}$ reported the rise of bound-hexose or-hexosamine level in sera of patients with inflammation or cancer. The finding of Niazi and States ${ }^{4}$ in 1948 that cancerous sera react strongly with diphenylamine has been also regarded as due to the increase of mucoproteins, because Werner and Odin ${ }^{51}$ remarked in 1952 that "sialoproteins" also give this reaction. The multiplicity of this group of substances in serum has become apparent in last decade by the works of Blix ${ }^{6)}$, of Rimington, ${ }^{78)}$ of Jayle, ${ }^{9110)}$ of Hewitt, ${ }^{11121)}$ of Seibert, ${ }^{13)}$ of Shetlar, ${ }^{14}$ of Dische, ${ }^{15116)}$ of Schmid, ${ }^{17118)}$ of Winzler, ${ }^{1920)}$ of our co-workers ${ }^{2122}$ ) and of many other authors.23) In 1952 Köiw and Grönwall ${ }^{24}$ devised a method for quantitative evaluation of the separated mucoproteins by PAS reaction after paper electrophoresis. It is now a routine procedure in clinical laboratories, although the procedure itself requests technical improvement (Björnesjö $\left.{ }^{25}\right)$. And it has thus become increasingly evident that some definitive relation exists between the quantity of those serum components and

* Read before the 31st Annual Meeting of the Japanese Biochemical Society, Sapporo, July 14-16, 1958. 230th report of Masamune and co-workers' "Biochemical Studies on Carbohydrates." 
various pathological processes (Winzler, ${ }^{26)}$ Greenspan ${ }^{27)}$, Goa ${ }^{28)}$, Jayle and Boussier $\left.{ }^{10}\right)$. Nevertheless, many problems still remain to be elucidated about the qualitative-chemical differences of those mucoproteins particularly in connection with systemic pathogenesis of cancer and inflammation.

We are concerned with the chemical qualitative respects of the urinary mucoproteins and particularly with the question whether any specific mucoprotein representing the pathogenic process of canceration exists or not. At first, attempts were made to distinguish the mucoprotein fraction adsorbable to benzoic acid of cancerous, inflammatory and normal urines from one another, whereby a characteristic strongly acidic spot or spots appearing on electrophoresis and a characteristic peak or peaks occurring on ion-exchange chromatography were noticed in the case of cancerous urine. Looking further on for the cancer-specific component among urinary muco-substances, substances were encountered unexpectedly, which are acidic, freely dialyzable through cellophane membrane but not through cellophane membrane coated with celloidin and freely soluble in $90 \%$ ethanol or $99 \%$ methanol but not in absolute ethanol nor in acetone. Because of smallness of molecule, they are not to be called " mucoproteins" but more appropriately " mucopolypeptides." At least seven such mucopolypeptides were demonstrated in cancerous urine after paper electrophoresis at pH 3.6 and more than ten after anion-exchange chromatography with gradient elution. Increase of one of them has been proved to be fairly specific to cancer, others being detectable also in normal and inflammatory urines. This cancer-specific, strongly acidic mucopolypeptide is named " $\kappa$-mucopolypeptide" tentatively. Its quantitative composition and comparison of it with the other acidic mucopolypeptides with respect to structure will be accounted for in a forthcoming paper.

\section{EXPERIMENTAL}

\section{Methods}

\section{Preparation of the acid mucopolypeptide fraction}

A fresh urine is distilled in vacuo to dryness, the residue is dissolved in water of one tenth the original urine volume, and absolute ethanol is added to $90 \%$. The bulky precipitate is centrifuged off and discarded, and the supernatant is distilled to dryness. The residue here is dissolved in water of one fiftieth the original urine volume and precipitated by addition of ethanol to $90 \%$. Spun down. The saturated lead acetate in $90 \%$ ethanol is added to the supernatant under agitation until no more precipitate comes out, followed by centrifugation. The centrifugate is freed from lead by stirring in the saturated sodium bicarbonate, and to the clear solution is added again ethanol to $90 \%$. The centrifuged super- 
natant fluid given is distilled to dryness, dissolved in methanol of one hundredth the original urine volume and precipitated with ten volumes of acetone. Per $300 \mathrm{cc}$. of urine of sp. gr. 1.015 were yielded $150 \mathrm{mg}$. in averages from urine of patients with cancer or inflammation, $80 \mathrm{mg}$. in averages from that of non-inflammatory patients and from that of normals.

Apparatus for paper electrophoresis

The semi-closed strip method of horizontal type ${ }^{29)}$ was employed. The closet and the electrode vessels are made with wooden boards coated with a plastic paint. The size of the parts are shown in Fig. 1. The frame to support the paper sheet is made of plastic material as shown in Fig. 2. It can support a $30 \mathrm{~cm}$. wide square of paper and is very convenient not only for two-dimensional electrophoresis of one sample but also for simultaneous one-dimensional electrophoresis of many samples. Power supplier : D. C. ; max. load $1000 \mathrm{~V}$, max. current $80 \mathrm{~mA}$. This apparatus was purchased from the Kyowa Institute of Applied Physics, Tokyo.

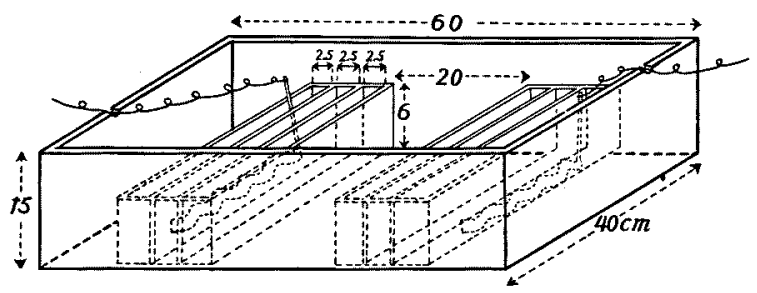

Fig. 1. Cabinet for paper electrophoresis containing four troughs for the buffer solution and two troughs for the electrodes, all made of wooden boards coated with a plastic paint. It is covered with a sheet of glass plate.

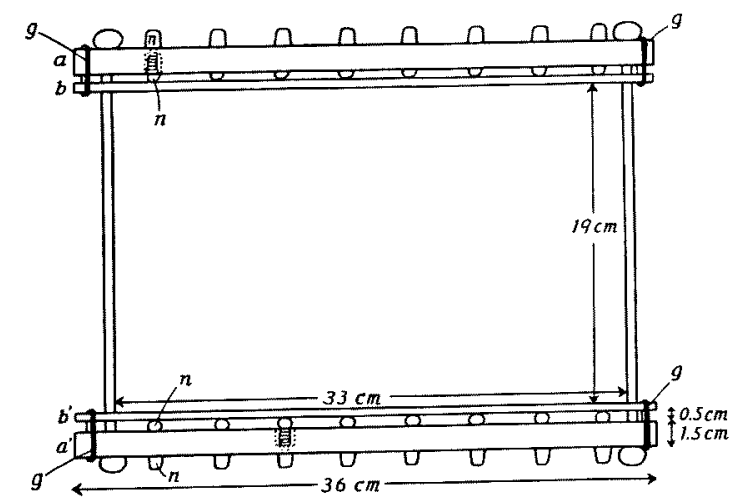

Fig. 2. Frame made of plastic material for holding a paper square. The paper sheet is held tightly between bars $b$ and $b^{\prime}$ by means of the nobs $(n)$ which are fixed on bars $a$ and $a^{\prime}$ with stainless wire springs. $a$ and $a^{\prime}$ are tightly bound with $b$ and $b^{\prime}$ respectively with gum bands $(g)$. 
Buffer solutions used

A buffer of $\mathrm{pH} 3.6$, which was a mixture of $1 M$ pyridine and $1 M$ acetic acid in the volume proportion of $1: 8$, a borate buffer of $\mathrm{pH} 8.6$ composed of 5.5 parts of $0.05 M$ borax $\left(19.105 \mathrm{~g}\right.$. of $\mathrm{Na}_{2} \mathrm{~B}_{4} \mathrm{O}_{7} \cdot 10 \mathrm{H}_{2} \mathrm{O}$ in l l. $\mathrm{H}_{2} \mathrm{O}$ ) and 4.5 parts of $0.2 \mathrm{M}$ boric acid (12.36 g. of $\mathrm{H}_{3} \mathrm{BO}_{3}$ in $1 l . \mathrm{H}_{2} \mathrm{O}$ ) by volume, and $0.1 \mathrm{M}$ borax-HCl buffer of the same $\mathrm{pH}$ prepared by dissolving $25.222 \mathrm{~g}$. of $\mathrm{Na}_{2} \mathrm{~B}_{4} \mathrm{O}_{7} \cdot 10 \mathrm{H}_{2} \mathrm{O}$ in $340 \mathrm{cc}$. of $0.2 \mathrm{~N} \mathrm{HCl}$ with subsequent addition of water to $1 l$. were employed for electrophoresis. The latter borate buffer was used also for ion exchange chromatography.

Demonstration of $\kappa$-mucopolypeptide among other mucopolypeptides by electrophoresis

In the early stage of cancer when the concentration of $\kappa$-mucopolypeptide in the acid mucopolypeptide fraction is low, it is preferable to employ the two-dimensional method because the separation is achieved more sharply. Despite of the incomplete separation, the one-dimensional method has a merit in the point that several specimens including the control can be run in parallel under exactly the same conditions or their component spots can be scanned photodensitometrically.
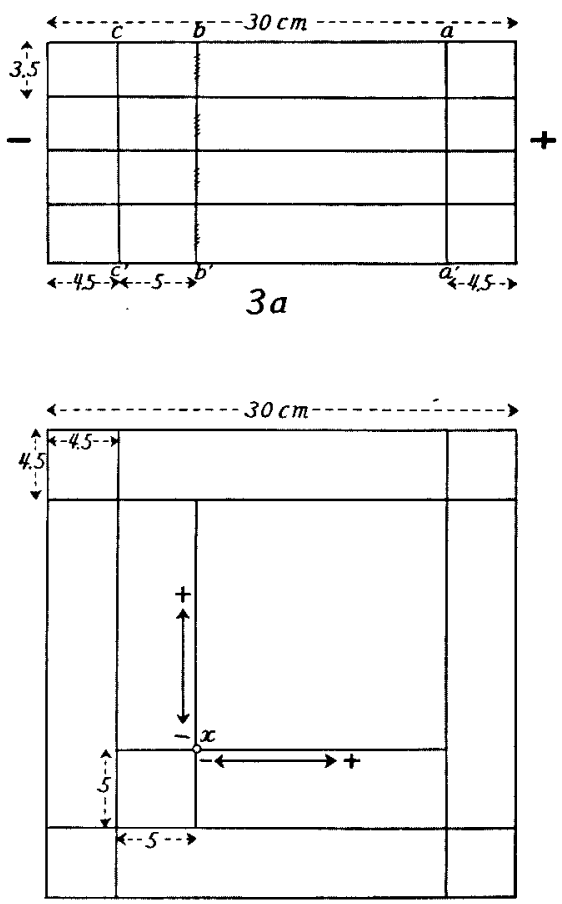

Fig. 3. Size of the parts in the paper sheets for one-dimensional (3a) and two-dimensional (3b) electrophoreses. 


\section{Electrophoresis}

Toyo Roshi filter paper No. 51 is used throughout the experiment. Pencil lines are drawn on the paper as shown in Fig. 3, and $0.03 \mathrm{cc}$. of a $50 \%$ solution of the above fraction is put on the $b-b^{\prime}$ line in paper $3 \mathbf{a}$ or double the volume of the solution on point $x$ in paper $\mathbf{3 b}$. The sheet dried is sprayed evenly with the acetic acid-pyridine buffer of $\mathrm{pH} 3.6$, plenty enough to avoid centripetal hydrodynamic flow from both the buffer troughs, fixed on the frame and settled between the two buffer troughs, so as line $c-c^{\prime}$ faces cathode and line $a-a^{\prime}$ faces anode in the case of one-dimensional electrophoresis. The two buffer troughs are connected with each other and the outer trough with the electrode vessel by means of a paper strip or agar bridges, and the levels of the pair of the inner buffer troughs are equilibrated by a tubing. The nonpolar electrodes are constructed beforehand in $1 \% \mathrm{KCl}-\mathrm{Ag}-\mathrm{AgCl}$ system. A drop of acid fuchsin is put beside each of the sample spots. Electricity is flowed at constant $200 \mathrm{~V}$ or at constant current $0.35 \mathrm{~mA}$ per $\mathrm{cm}$. width of paper. Duration of test 24 hours. Temperature below $10^{\circ} \mathrm{C}$ (In summer, the cabinet is cooled with chunks of ice placed on the bottom). Then, the paper is dried by a drier. In the case of two-dimensional electrophoresis, the dried sheet is further sprayed with the borax-boric acid buffer of $\mathrm{pH} 8.6$ and settled in the assemblage to process the secondary run at $400 \mathrm{~V}$ of electricity for 2 hours.

After thorough drying of the paper by mild heating, the spots are indicated by an appropriate reaction. As regards that reaction were examined such reagents as $\mathrm{NaIO}_{4}-\mathrm{AgNO}_{3}-\mathrm{NaOH}^{30)}$, p-dimethylaminobenzaldehyde ${ }^{31)}, \mathrm{HIO}_{4}$-Shiff, ${ }^{24)}$ ninhydrin, aniline phthalate, Toennies' platinic iodide reagent for SH-group ${ }^{32}$ ) iodine vapor $\left(\mathrm{Kent}^{33)}\right), \mathrm{Cl}_{2^{-}}-\mathrm{ClO}_{2^{-}}$ benzidine (Raydon ${ }^{34)}$, Reindel and $\mathrm{Hoppe}^{35)}$ ), $\alpha$-naphthol- $\mathrm{H}_{2} \mathrm{PO}_{4}{ }^{36)}$ and

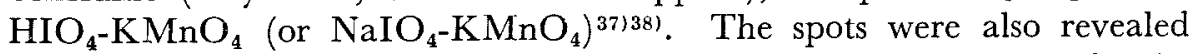
under an ultraviolet lamp. The last two of the reagents were found satisfactory contrary to the others, by which the tests are time-consuming and tedeous or too nonspecific.

a) $\mathrm{HIO}_{4}-\mathrm{KMnO}_{4}$ method. Lemieux and $\mathrm{Bauer}^{37}$ and later on Wolfrom and Miller ${ }^{38}$ employed this reagent for the test of nonreducing sugars, but the reaction was let occur in an alkaline medium, whereby amino acids, peptides or even various cations react though faintly so that the method has been improved to avoid nonspecific reaction by conducting the assay in a slightly acidic medium as follows :- The paper is first sprayed with $2 \% \mathrm{HIO}_{4}$ (Merck New York), and after standing at room temperature for 8 to 10 minutes, again sprayed but with $2 \% \mathrm{KMnO}_{4}$ in water $(2 \%$ $\mathrm{KMnO}_{4}$ in $1 \%$ acetic acid when an alkaline buffer is used in electrophoresis). In 10-15 minutes, spots get colored yellow to brown against a purple background. The paper is washed with water well to remove 
the purple $\mathrm{KMnO}_{4}$ colour as far as possible and air-dried. Brown spots indicate the presence of periodate-reactive substances. The specificity of the reaction was checked with amino acids, amines, urea and creatinine, all of which proved inert.

The reaction can occur after ninhydrin reaction without altering its sensitivity. In quantitative densitometry by means of a Beckman scanning meter, the time of reaction and the temperature should be controlled. Five minutes oxidation with periodate at $10-15^{\circ} \mathrm{C}$, ten minutes exposure to permangate at the same temperature and 10 minutes washing with tap water in turn meet the purpose.

b) $\alpha$-Naphthol- $\mathrm{H}_{3} \mathrm{PO}_{4}$ method

The paper on which samples have migrated electrophoretically is sprayed with a mixture of 9 parts of $1 \% \alpha$-naphthol in ethanol and 1 part of concentrated orthophosphoric acid and heated over an oven for about 5 minutes at $80^{\circ} \mathrm{C}$, until the coloration of spots reaches maximum. Overheating should be evaided. Pink, blue, violet and green spots are shown against a white background.

Assemblage for simultaneous ion exchange chromatography of three samples by gradient elution

Tiselius principle of gradient elution ${ }^{39)}$ allowing an exponential increase of eluting force was applied. In order to carry out chromatography of three different samples (cancerous, normal and inflammatory) under exactly the same conditions, the assemblage in Fig. 4 was used which can maintain the dropping rates of the eluate uniform and constant. A hypodermic syringe, through which a stainless stylet is run, is connected with the tip of a column to regulate the drop rate by pushing in or pulling out the stylet.

\section{Preparation of the column}

Commercial Dowex $1 \times 2$ in chloride form of mesh 200-400 is set free by washing with $2 \mathrm{~N} \mathrm{NaOH}$ and washed with water and $2 \mathrm{~N} \mathrm{HCl}$ in turn. The operation is repeated twice. The resulting Dowex $1 \times 2$ in chloride form was washed with changes of the $0.1 \mathrm{M}$ borax-HCl buffer of $\mathrm{pH} 8.6$ until no more occurrence of $\mathrm{pH}$ change of the buffer, poured into a $1.3 \mathrm{~cm}$. wide chromatography tube to make a column of $15 \mathrm{~cm}$. height and washed with the borate buffer diluted 16 times $(0.00625 M)$.

Column chromatography

$300 \mathrm{mg}$. of the acid mucopolypeptide fraction of cancerous, inflammatory and normal urines are dissolved each in 1-2 cc. of water and added onto three columns separately. The chromatography tubes are combined with the assemblage shown in Fig. 4 , in which mixing bottle $b$ containing $750 \mathrm{cc}$. of the $0.00625 \mathrm{M}$ borax- $\mathrm{HCl}$ buffer of $\mathrm{pH} 8.6$ is surmounted with a tubelet connecting it with reservoir a containing $1200 \mathrm{cc}$. of the $0.1 \mathrm{M}$ 


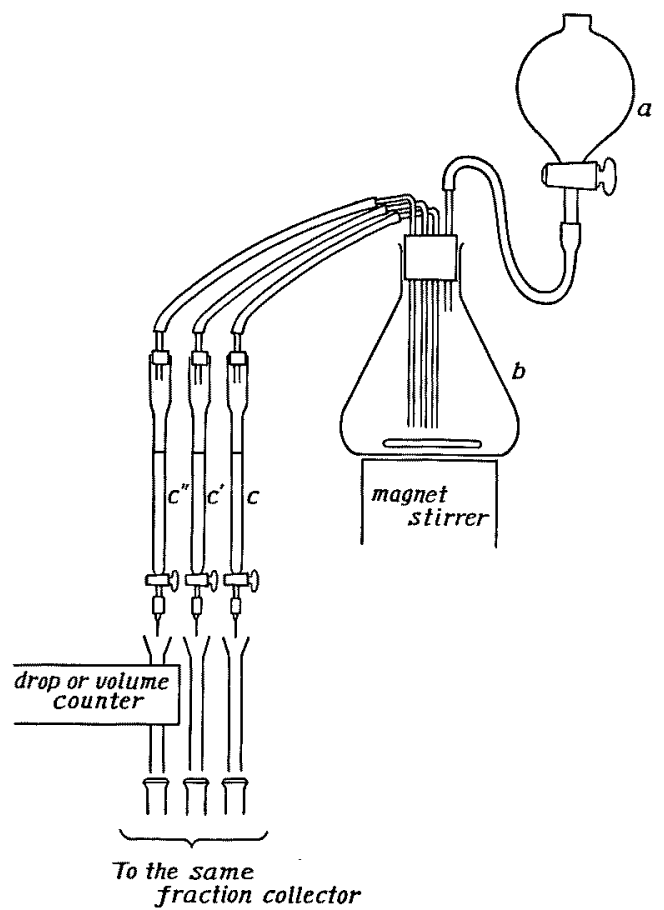

Fig. 4. Assemblage for simultaneous chromatography of three samples. Three tubings connect three different chromatographic tubes $\left(c-c^{\prime \prime}\right)$ with a $1 \mathrm{l}$. mixing bottle $(b)$ which is surmounted with a dropping funnel $(a)$.

borax-HCl buffer of the same $\mathrm{pH}$ value. A magnetic stirrer is set beneath the mixing bottle. The dropping rate is so adjusted as one drop falls in 8 to 10 seconds. When the $0.1 M$ borate buffer in the reservoir is exhausted, $900 \mathrm{cc}$. of $0.5 M$ acetic acid is replaced for continuous elution. Subsequently successive elutions with $0.5 \mathrm{M}$ formic acid and $0.33 \mathrm{M}$ hydrochloric acid were usually processed in a similar manner. The effluent is collected in $10 \mathrm{cc}$. fractions.

$1 \mathrm{cc}$. aliquots of each fraction are analyzed by a quantitative Molisch reaction according to Dische ${ }^{40)}$ (Extinctions at $570 \mathrm{~m} \mu$ are measured after the reaction) and another $3 \mathrm{cc}$. aliquots are examined regarding the ultraviolet absorption at $280 \mathrm{~m} \mu$.

\section{Results with Discussion}

One-dimensional electrophoretic patterns consist of at least seven spots in case of cancerous urine and five to six spots in cases of normal and noncancerous pathological urines (See Fig. 5 and 6). The spots are designated A, B, C, D, E, F and $\mathrm{G}$ in the sequence from the slowest to the fastest. Sometimes spot $\mathrm{H}$ is observed besides, irrespective of the kind 


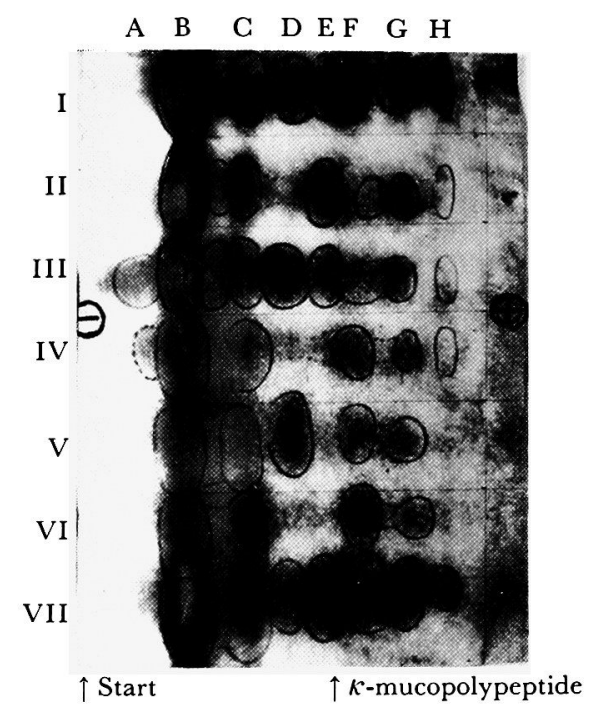

Fig. 5. Paper electrophoretic paptterns of the mucopolypeptide fraction of urines of patients with gastric cancer at the early stage (I), gastric cancer with liver metastasis (II), hepatoma (III), gastric ulcer (V), tuberculosis of lung (VI) or advanced gastric cancer with ascites (VII), and of a pregnant (fourth mouth) women (IV). The patterns were indicated by periodate-permanganate method (Oxidize with $\mathrm{KIO}_{4}$, spray with $\mathrm{KMnO}_{4}$ and wash with water). Note appearance of $\kappa$-mucopolypeptide (area E) in case of malign tumors (I, II, III and VII) but not in other diseases nor in pregnancy. Regarding conditions for the electrophoresis, see the text.

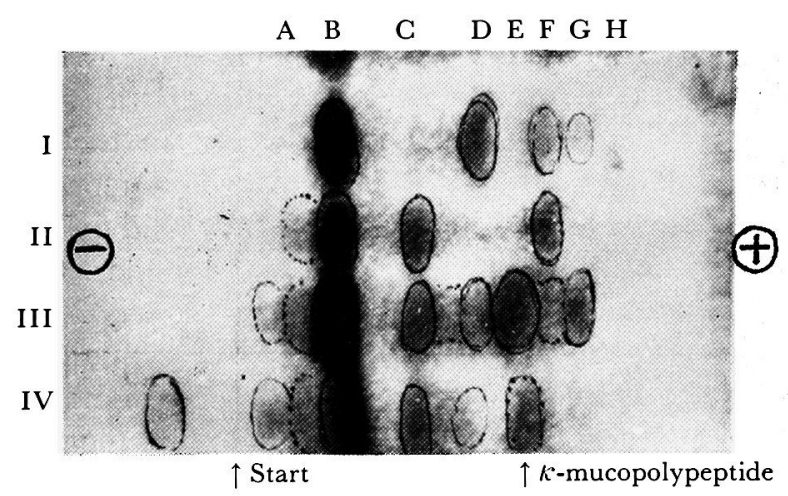

Fig. 6. Paper electrophoretic patterns of the mucopolypeptide fraction of urines of patients with gastric ulcer (I), tuberculosis of lung (II), gastric cancer (III) or leucemia (IV). Note the occurrence of spots at positions corresponding to $\kappa$-mucopolypeptide ( $\mathrm{E}$ area) in III and IV.

of disease. The spots react with $\mathrm{NaIO}_{4}-\mathrm{KMnO}_{4}$ and are all colored brown but in the order of B, D, E, F, C, A and G in strength, the last spot being the weakest. However, their reactivities with the $\alpha$-naphthol- 
phosphoric acid reagent are conspicuously different. Spot B gets colored brownish or greenish purple, $A$ and $C$ faintly red, and $G$ and $E$ intensely purple, while $\mathrm{D}$ remains almost uncolored.

As $B$ and $C$ are reactive towards p-dimethylaminobenzaldehyde and Toennies' SH-reagent, they contain sialic acid and an amino acid grouping possessing the SH-radical in the molecule, in other words, they belong to a cathegory of "sialoproteins" or "neutral glucidamins", resembling $\alpha_{1}$ - or $\alpha_{2}$ - acid glycoprotein in Schmid's or Winzler's terminology. In contrast to those substances, that forming spot $\mathrm{E}$ is quite unique in composition, because it gives spots at the positions corresponding to glucosamine, a methylpentose, an unidentified reducing aminosugar and such amino acids as aspartic and glutamic acids, glycine, serine, alanine and so on but none of cyclic amino acids nor hexone bases, when paper-chromatographed after hydrolysis, and also shows the positive reaction for hydrolyzable sulfur. Quantitative estimation of the zones of the hydrolysate after electrophoresis on "Geon "-polyvinyl resin"1) or photodensitometric scanning of the spots after paper-electrophoresis by means of a Beckman photo-scanning meter or even by comparison of the spots by the naked eye revealed in case of cancer i) appearance or marked increase of spot $\mathrm{E}$ which is reactive toward periodate-permanganate and also towards $\alpha$-naphthol-phosphoric acid, and ii) increase of spot $\mathrm{G}$ which is reactive towards periodate-permanganate but not towards $\alpha$-naphthol-phosphoric acid. A unique spot migrating towards cathode in case of monocytic leucemia is also remarkable. In tuberculosis marked increase of spot $\mathrm{F}$ is noticed. Increase or appearance of spot $\mathrm{E}$ has never been experienced in any diseases other than cancer. It is more pronounced at the advanced stage than at the early stage of cancer. The distance of the spot (center), which owes to $\kappa$-mucopolypeptide, from the start varies from 8 to $10 \mathrm{~cm}$. The one-dimensional electrophoresis patterns represented photodensitometrically by means of a Beckman scanning meter are shown in Fig. 7. It is of great interest that different spots increase or decrease according to the kind of disease.

Two-dimensional paper electrophoresis can resolve the acid mucopolypeptide fraction into at least eight components much more sharply than the one-dimensional, although it requests more time and skill. Fig. 8 shows examples of the patterns.

A number of peaks are well separated by ion exchange chromatography as illustrated in Fig. 9, 10 and 11 . Of the fast occurring peaks, one which is especially high in cancer might correspond to spot B in the electrophoresis pattern, and a peaks pecific to cancer which coincides with the spot of $\kappa$-mucopolypeptide after electrophoresis is demonstrated soon after commenecment of the acetic acid elution. The latter peak is Molisch-positive but devoid of ultraviolet absorptivity. Thus, besides the peaks common 

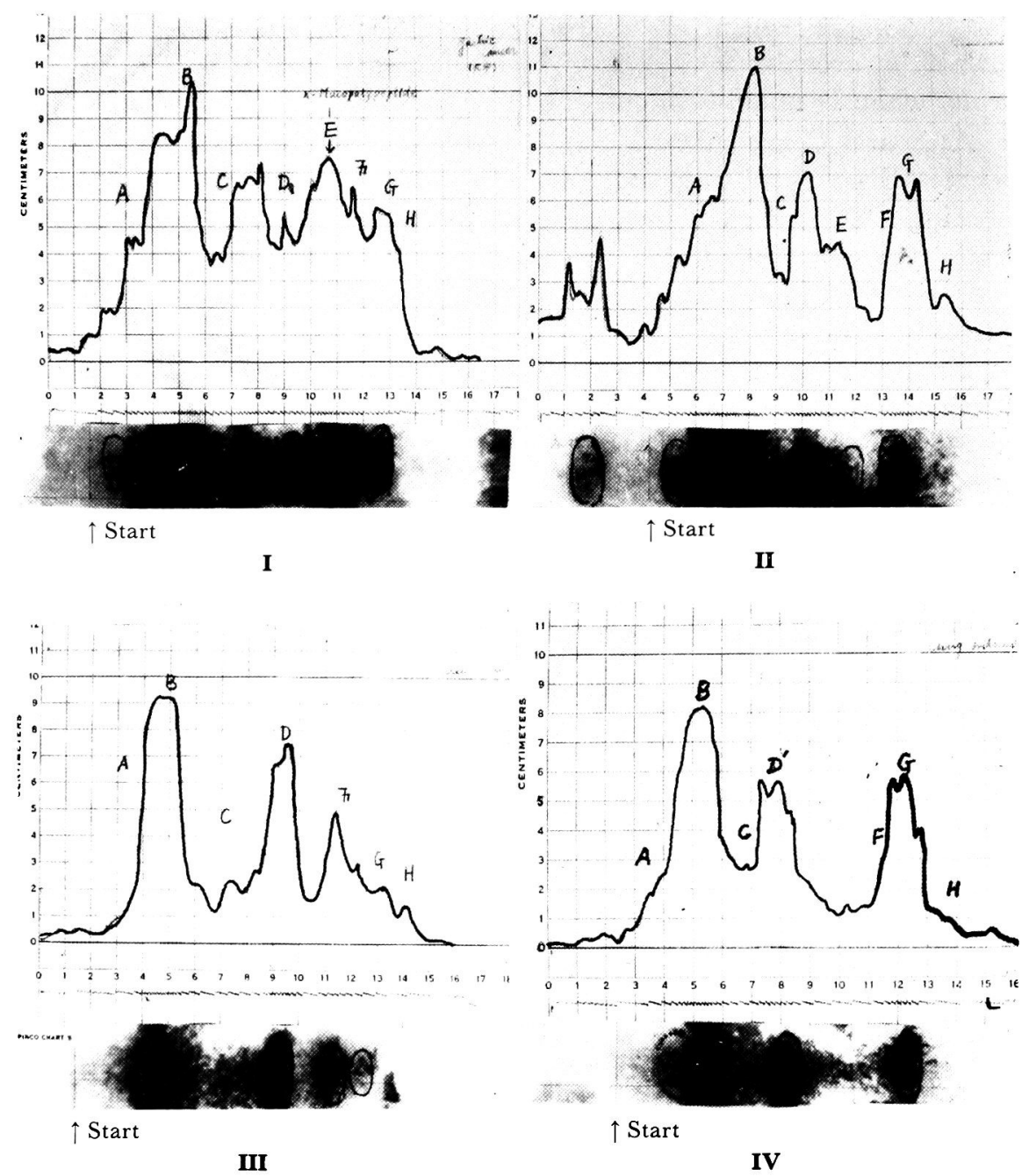

Fig. 7. Paper electrophoretic patterns photodensitometrically scanned immediately after periodate-permanganate staining of the urinary mucopolypeptides of various diseases. Note appearance of the $k$-mucopolypeptide peak at $\mathrm{E}$ between $\mathrm{D}$ and $\mathrm{F}$ in cases of malign tumor. $\mathbf{I}$ : Gastric cancer with metastasis in liver. II : Monocytic leucemia. III : Gastric ulcer. IV : Tuberculosis of lung.

to normal and pathological urines, a peak or peaks which reflect particular types of disease are also discerned in the ion-exchange chromatograms. The technique requires a long time, but the patterns obtained are quite characteristic and decisive for diagnosis. The procedure to get such patterns may be called "muco-urinography", and the patterns "muco-urinograms". 


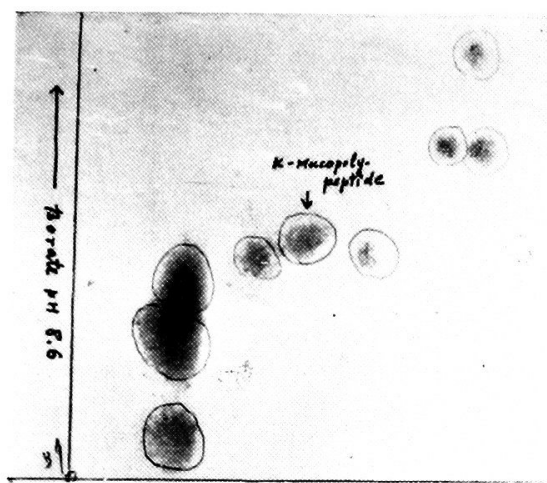

Acetic acid-pyridine $\mathrm{pH} 3.6 \longrightarrow$ Gastric cancer

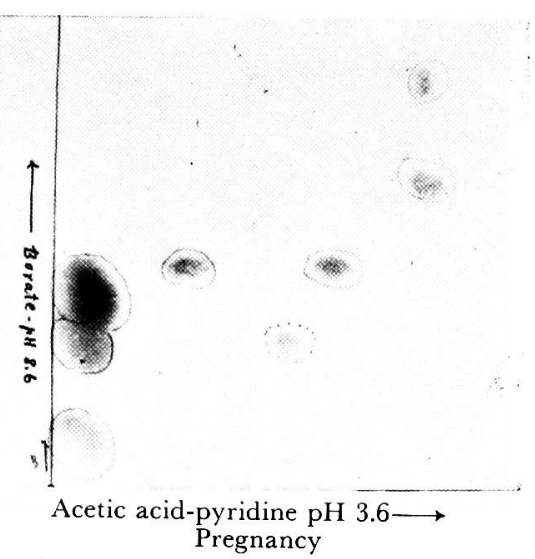

Fig. 8. Two-dimensional electrophoretic patterns of the mucopolypeptide fraction of urines of a patient with gastric cancer (left) and of a pregnant woman (right). The first run was effected in $0.1 \mathrm{M}$ pyridine-acetic acid buffer of $\mathrm{pH}$ 3.6 and the second in $0.1 M$ borax-boric acid buffer of $\mathrm{pH}$ 8.6. The direction of the anode is coincident with the arrow mark. Regarding conditions else of electrophoresis see the text. The spots were oxidised with $\mathrm{NaIO}_{4}$ in $1 \%$ acetic acid for 5 minutes at $10^{\circ} \mathrm{C}$ at first and then exposed to $2 \%$ potassium permanganate for 10 minutes at $10^{\circ} \mathrm{C}$ followed by washing with water for 10 minutes. Note clear-cut separation of the components from one another in the both patterns and marked occurrence of $\kappa$-mucopolypeptide in the left.
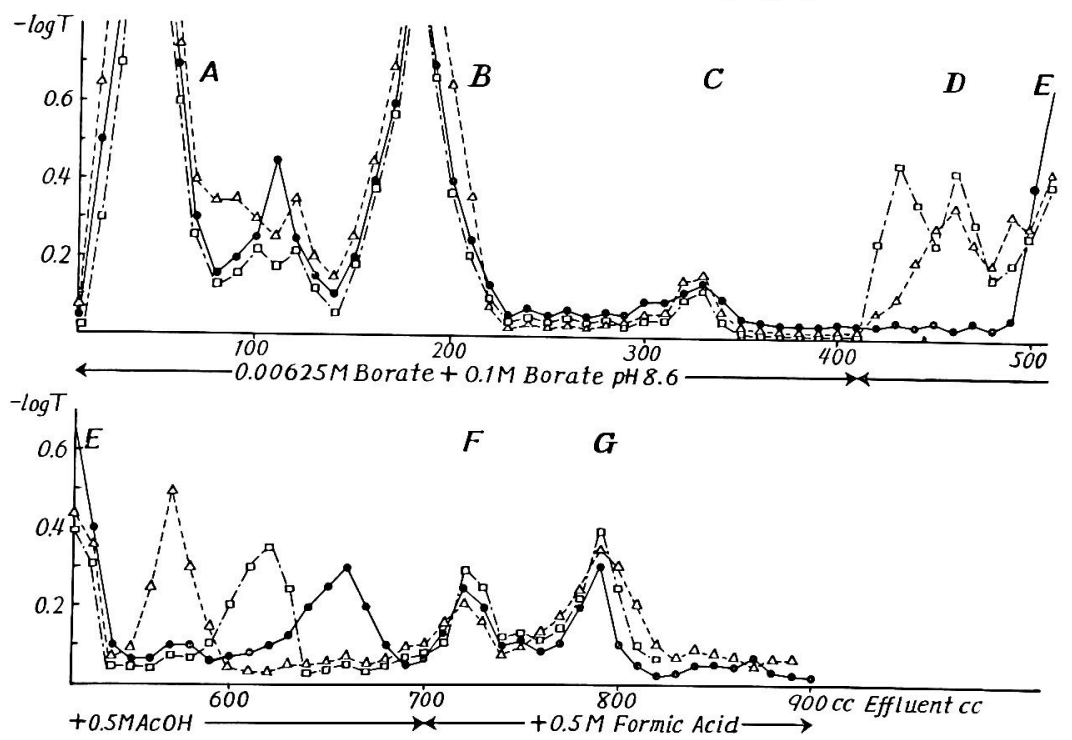

Fig. 9. Dowex $1 \times 2$ chromatograms of the mucopolypeptide fraction of urines from a patient with gastric cancer $(\triangle-\triangle-\triangle)$, a patient with monocytic leucemia $(\square--\square--\square$ ) and a normal (- The extinctions at $570 \mathrm{~m} \mu$ of the fractions were measured after quantitative Molisch reaction. Notice that a peak occurs at the first stage of the acetic acid elution in the cases of cancer and leucemia but not in the case of normal. 


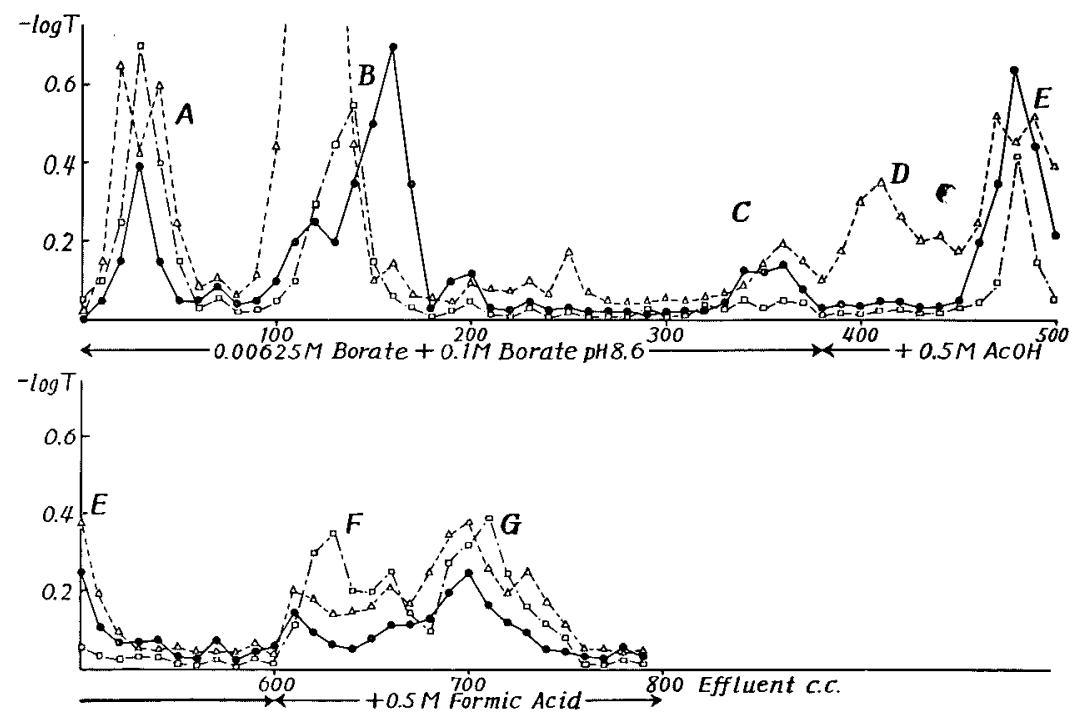

Fig. 10. Dowex $1 \times 2$ chromatograms of the mucopolypeptide fraction of urines from a patient with gastric cancer $(\Delta--\Delta--\Delta)$, a patient with gastric ulcer (-O) and a patient with hepatitis acuta $(\square--\square--\square$ ). The extinctions at $570 \mathrm{~m} \mu$ were measured after quantitative Molisch reaction of the fractions. Note the occurrence of a peak at the first stage of the acetic acid elution only in the case of cancer.

It is strongly suggested from electrophoretic patterns and mucourinograms that the special mucopolypeptides that increase or appear reflect responsible pathogenic processes inflammation, degeneration, tissue proliferation, systemic alarming reaction, malign growth etc. Prospectively thinking, the muco-urinographic analysis would make an epoch not only for better understanding of urinary colloids but also for fundamental utilization of them in prognosis and diagnosis of various pathological processes.

In Table I are summarized the results of assay for $\kappa$-mucopolypeptide compared with those of clinical diagnosis.

\section{Summary}

1. A cancer-specific acid mucopolypeptide was found among other urinary muco-polypeptides and designated " $k$-mucopolypeptide".

2. Methods for detecting it in cancerous urines are described.

The writers express their hearty gratitude to the Ministry of Education for a grant in aid to us trough the Grant Committee for Medical, Dental and Pharmaceutical Researches. 


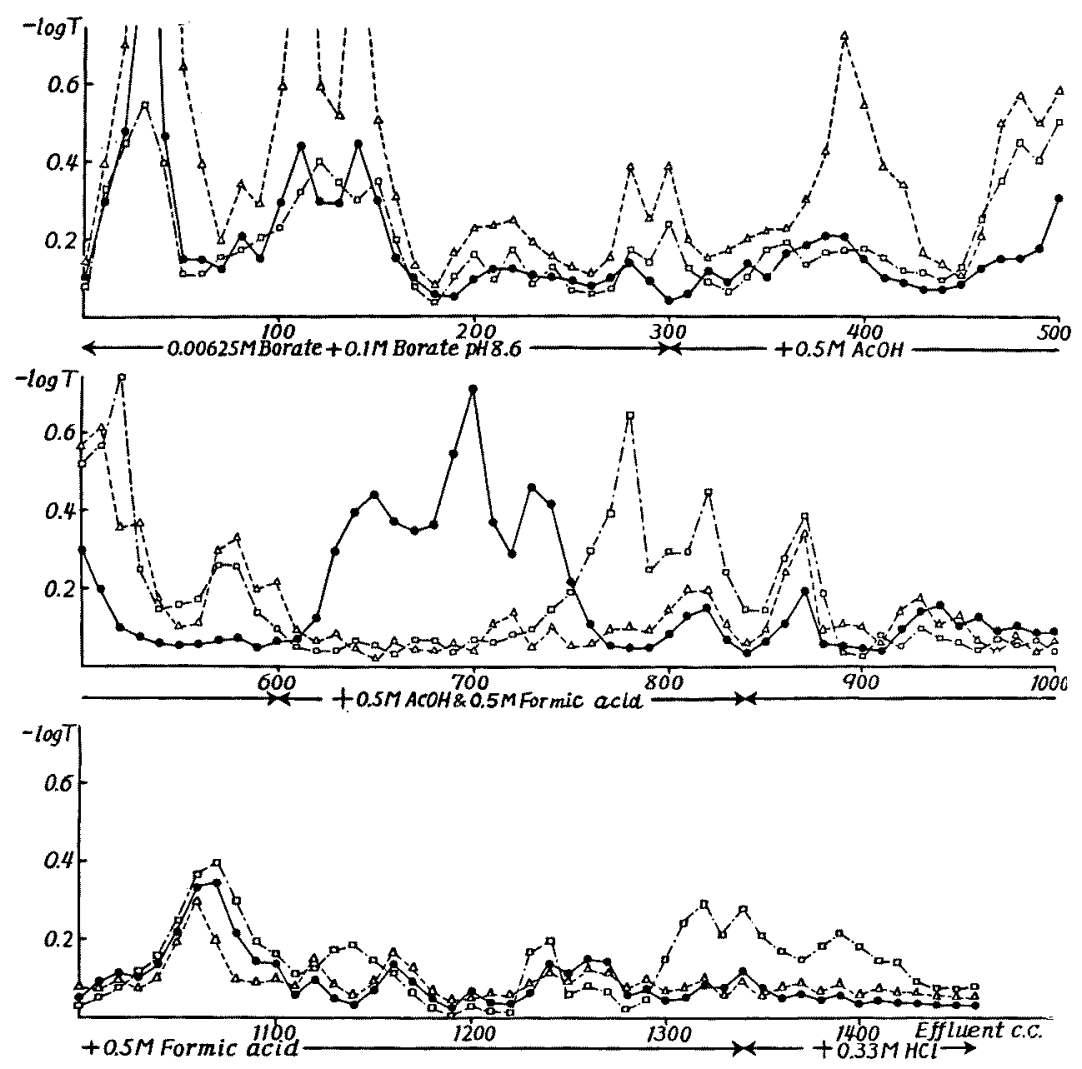

Fig. 11. Dowex $1 \times 2$ chromatograms of the urinary mucopolypeptide fraction of patients with gastric cancer $(\triangle \cdots \Delta \cdots \Delta)$, gastric ulcer $(-0)$ or tuberculosis of lung $(\square \ldots \square-\cdots \square$ ). The gradient elution here was made by inserting a mixture of equal parts of $1 M$ acetic acid and $1 M$ formic acid between $0.5 \mathrm{M}$ acetic acid and $0.5 \mathrm{M}$ formic acid, and the extinctions at $575 \mathrm{~m} \mu$ of the fractions after quantitative Molisch reaction were measured. Note the occurrence of a peak at the first stage of the acetic acid elution only in the case of cancer.

\section{References and Notes}

1) Masamune, Hakomori, Kaketa \& Sugo, Tohoku J. Exp. Med., this volume p. 371.

1a) Lustig \& Langer, Biochem. Z., 1931, 242, 320.

2) Nilsson, ibid., 1937, 291, 254.

3) West \& Clarke, J. Clin. Invest., 1938, 17, 173.

4) Niazi \& States, Cancer Res., 1948, 8, 653.

5) Werner \& Odin, Acta. soc. med. Upsal., 1952, 57, 227, 230.

6) Blix, Tiselius \& Svensson, Biochem. J., 1941, 37, 485.

7) Rimington, Ergebn. Physiol., 1933, 35, 712.

8) Rimington, Bioch. J., 1940, 34, 931. 
TABLE I

Diagnosis of Cancer by Assay for $\kappa$-Mucopolypeptide in Urine

\begin{tabular}{|c|c|c|c|}
\hline \multicolumn{2}{|c|}{ Clinical diagnosis } & \multirow[t]{2}{*}{ Treatment received } & \multirow{2}{*}{$\begin{array}{c}\text { Occurrence of } \\
\kappa \text {-mucopoly- } \\
\text { peptide }\end{array}$} \\
\hline Gastric cancer & Early stage, no metastasis & & \\
\hline Gastric cancer & Early stage, no metastasis & & + \\
\hline Gastric cancer & Metastasis in liver & $\begin{array}{l}\text { Laparotomy, chemo- } \\
\text { therapy }\end{array}$ & + \\
\hline Gastric cancer & $\begin{array}{l}\text { Metastasis in liver with perito- } \\
\text { nitis carcinomatosa }\end{array}$ & Chemotherapy & + \\
\hline Gastric cancer & $\begin{array}{l}\text { Metastasis in liver, with Vir- } \\
\text { chow noduli and peritonitis car- } \\
\text { cinomatosa }\end{array}$ & Chemotherapy & + \\
\hline Gastric cancer & $\begin{array}{l}\text { Postoperative recurrence, metas- } \\
\text { tasis in liver }\end{array}$ & Chemotherapy & + \\
\hline Gastric cancer & $\begin{array}{l}\text { Metastasis in liver with perito- } \\
\text { nitis carcinomatosa }\end{array}$ & Chemotherapy & + \\
\hline Esophagus cancer & $\begin{array}{l}\text { Metastasis in liver and media- } \\
\text { stinal cavity }\end{array}$ & Chemotherapy & + \\
\hline Uterus cancer & $\begin{array}{l}\text { Origin at portio vaginalis, } 4 \text { th } \\
\text { grade }\end{array}$ & $\begin{array}{l}\mathrm{x}-\text { Ray and radium } \\
\text { irradiation }\end{array}$ & + \\
\hline Uterus cancer & $\begin{array}{l}\text { Origin at portio vaginalis, cir- } \\
\text { cumscriptive }\end{array}$ & $\begin{array}{l}\text { x-Ray and radium } \\
\text { irradiation }\end{array}$ & \\
\hline Vaginal cancer & $\begin{array}{l}\text { Origin at labium minor, no } \\
\text { metastasis }\end{array}$ & Radium irradiation & \\
\hline Breast cancer & Early stage & $\mathrm{x}$-Ray irradiation & - \\
\hline Monocytic leucemia & & Chemotherapy & + \\
\hline Hepatoma & Primary & Chemotherapy & + \\
\hline Mediastinal tumor & & $\mathrm{x}$-Ray irradiation & \pm \\
\hline $\begin{array}{l}\text { Chorionepithelioma } \\
\text { malignum }\end{array}$ & $\begin{array}{l}\text { Postoperative recurrence, with } \\
\text { lung metastasis }\end{array}$ & & \pm \\
\hline Hodgkin's disease & & Chemotherapy & - \\
\hline Tuberculosis of lung & Productive & Chemotherapy & - \\
\hline Tuberculosis of lung & Exudative & Chemotherapy & - \\
\hline Pregnancy & 4th month & & - \\
\hline Pregnancy & 10 th month & & - \\
\hline Pregnancy & 10th month & & \pm \\
\hline Puerperal fever & & Chemotheropy & - \\
\hline Rheumatic fever & & & - \\
\hline Normal & & & - \\
\hline Normal & & & - \\
\hline Gastric ulcer & $\begin{array}{l}\text { Niche remarked on } x \text { ray exa } \\
\text { mination }\end{array}$ & & \\
\hline Gastric ulcer & $"$ & & - \\
\hline Gastric ulcer & $"$ & & - \\
\hline
\end{tabular}


9) Jayle \& Abdellatif, Bull. soc. chim. biol., Paris, 1946, 28, 80.

10) Jayle \& Boussier, Expos. ann. biochem. med., 1955, 17, 157.

11) Hewitt, Biochem. J., 1937, 31, 360.

12) Hewitt, ibid., 1938, 32, 1554.

13) Seibert, Pfaff \& Seibert, Arch. Biochem., 1948, 18, 279.

14) Shetlar, Shetlar, Richmond \& Everett, Cancer Res., 1950, 10, 681.

15) Dische, Biochem. Z., 1928, 201, 74.

16) Dische \& Osnos, Fed. Proc., 1952, 11, 202.

17) Schmid, J. Amer. Chem. Soc., 1953, 75, 60.

18) Schmid, ibid., 1955, 77, 742.

19) Weimer, Mehl \& Winzler, J. Biol. Chem., 1950, 185, 561.

20) Winzler, Devor, Mehl \& Smyth, J. Clin. Invest., 1948, 27, 609.

21) Ozaki, J. Biochem. (Japan), 1936, 24, 73.

22) Osaki \& Yosizawa, Tohoku J. Exp. Med., 1949, 51, 57.

23) Regarding reviews of those accounts see Winzler, Advances in cancer research, Academic Press, New York, 1953, 1, 503; Methods of biochemical analysis, Interscience Publishers, New York and London, 1955, 2, 279.

24) Köiw \& Grönwall, Scand. J. Clin. \& Lab. Invest., 1952, 4, 224.

25) Björnesjö, ibid., 1955, 7, 153.

26) Winzler, Chemistry \& biology of mucopolysaccharides, Charchill, London, 1958, p. 245.

27) Greenspan, Arch. Intern. Med., 1954, 93, 803.

28) Goa, Scand. J. Clin. \& Lab. Invest., 1955, Suppl. 22.

29) Block, Durrum \& Zweig, Paper chromatography \& paper electrophoresis, Academic Press Inc., New York, 1955, p. 349 (Table I).

30) After oxidation with $\mathrm{NaIO}_{4}$, the paper was treated by Travelyan and others' procedure (Trevelyan, Procter \& Harrison, Nature, 1950, 166, 444). Mucoproteins can be revealed as brown to black spots on a white background, but the specificity of this indication method is very low.

31) Dissolve $0.8 \mathrm{~g}$. of Ehrlich aldehyde reagent in a mixture of $30 \mathrm{cc}$. of conc. $\mathrm{HCl}$ and $30 \mathrm{cc}$. of abs. ethanol. Sprayed with the reagent and warmed gently, sialoprotein spots get colored purple.

32) Toennies \& Kolb, Anal. Chem., 1951, 23, 823-826.

33) Greenway, Kent \& Whitehouse, Research, 1953, 6, Suppl. No. 1, 6 ; Cited in C. A. 1954, 48, 1203.

34) Raydon \& Smith, Nature, 1952, 169, 922.

35) Reindel \& Hoppe, Naturwissenschaften, 1953, 40, 221.

36) Rachinskii \& Knyazyatova, Doklady Aka. Nauk S.S.S.R., 1952, 85, 1119 ; Cited in C. A., 1955, 47, 448 and by Block et al. (29)), p. 136.

37) Lemieux \& Bauer, Anal. Chem., 1954, 26, 920.

38) Wolfrom \& Miller, ibid., 1956, 28, 1037.

39) Alm, Williams \& Tiselius, Acta chem. Scand., 1952, 6, 826; Hagdahl, Williams \& Tiselius, Arkiv. kemi, 1952, 4, 193 ; Cited in Lederer \& Lederer, Chromatography, Elsevier Publ., Amsterdam, London, New York \& Princeton, 1957, p. 43.

40) Dische, Mikrochemie, 1929, 7, 33.

41) Geon-polyvinyl resin of mesh 200-400, Geon Co., Cleaveland, Ohio was used. 